\title{
Iron deficiency and iron treatment in the fetal developing brain - a pilot study introducing an experimental rat model
}

\author{
Torben Moos*, Tina Skjørringe and Lars Lykke Thomsen \\ From 2nd International Conference on Maternal and Newborn Health: Translating Research Evidence to Practice \\ Belagavi, India. 26-27 March 2018
}

\begin{abstract}
Background: Iron deficiency is especially common in women during the reproductive age and it is estimated that $52 \%$ of pregnant women have iron deficiency anemia. Maternal iron deficiency with or without anemia in pregnancy may have consequences for the fetus, where it may have an impact on the cerebral development of the brain. Both animals and adult human studies support that iron deficiency affects psychomotor development, behavioral traits, and cognitive functions in the offspring. However, it has not yet been established whether the availability of sufficient iron is particularly important in certain phases during brain development, and whether possible damages are reversible if iron supplementation is provided during pregnancy. Here we report results from a pilot study in an experimental rat model suitable for introducing iron deficiency in the fetal rat brain.
\end{abstract}

Methods: The model was utilized for examination of the potential to reverse changes in fetal brain iron by maternal parenteral iron administration. Fertilized females subjected to iron deficiency without anemia were subcutaneously injected with iron isomaltoside at the day of mating (E0), 14 days into pregnancy (E14), or at the day of birth (Postnatal (P) 0). Blood, brain and liver in the offspring were examined on P0 or in adulthood on postnatal day P70.

Results: Maternal iron restriction during pregnancy led to significantly lower levels of iron in the brains of newborn rats compared to levels in pups of iron sufficient mothers. Females fed ID diet (5.2 mg/kg Fe) had offspring with significantly lower cerebral iron compared to a control group fed a standard diet (158 mg/kg Fe). Injection of IIM to pregnant ID females on E0 or E14 yielded normalization of Fe in the developing brain known to express elevated levels of capillary transferrin receptors, indicating that the administered iron passed the placenta and fetal blood brain barrier.

Conclusions: In future studies, this translational model may be applied to examine morphological and biochemical consequences of iron deficiency and iron deficiency treatment in the developing fetal brain.

Keywords: Brain, Development, Fetal, Iron, Pregnancy

\section{Background}

According to the World Health Organization (WHO), iron deficiency affects approximately $20 \%$ of the population worldwide equal to approximately 1.4 billion people. Iron deficiency is especially common in women during the reproductive age and in young children [1]. A major consequence of iron deficiency is anemia, and in developing

\footnotetext{
* Correspondence: tmoos@hst.aau.dk

Laboratory of Neurobiology, Biomedicine Group, Department of Health

Science and Technology, Aalborg University, Fr. Bajers Vej 3B, 1.216, DK-9220 Aalborg East, Denmark
}

countries, it is estimated that $52 \%$ of pregnant women have iron deficiency anemia [1]. The frequencies of iron deficiency anemia in the UK in the first, second, and third trimesters are approximately 2,8 , and $27 \%$, respectively [2].

Maternal iron deficiency anemia in pregnancy may have consequences for both mother [3] and fetus/newborn. Some consequences for the fetus include 'small for gestational age' (SGA) and intrauterine growth restriction (IUGR), which can complicate the neonatal period 
and by itself affect brain development of the fetus/newborn [4-6]. Iron is an essential co-factor for many enzymes, which are important in normal cell physiology, e.g. mitosis. Thus, there is a good reason to believe that iron deficiency in the developing brain even without fetal anemia may adversely affect the developing fetal brain [7]. In the central nervous system, iron is a co-factor for a variety of proteins and lipids vital for the normal cellular function. Iron is essential for cell division [8], including neuronal precursors of the developing brain, hence making gestational iron deficiency a serious challenge.

Iron deficiency in experimental animals affects dendritic growth, synaptic formation, and the function of oligodendrocytes, i.e. axon myelination [7, 9, 10]. Iron deficiency affects specific regions of the developing brain, including basal ganglia and hippocampus, which are involved in recognition memory, cognitive functions, and other higher cerebral functions [4, 11, 12]. Both experimental animals and adult human studies support the notion that iron deficiency affects psychomotor development, behavioral traits (anger, fear, anxiety), and cognitive functions in the offspring [7, 13-23]. However, it has not yet been established whether the availability of sufficient iron is particularly important in certain phases during brain development, and whether possible damages are reversible if maternal iron supplementation during pregnancy is applied. Further, little is known about transfer of iron across the placenta and the fetal bloodbrain barrier. Properly designed interventional trials of iron treatment controlling for cofactors, correct dosing, and way of administration etc. either as maternal treatment during pregnancy or in the neonates are still warranted. Animal models of iron deficiency treatment may provide some information of how iron deficiency effects morphological brain development and translational animal models are relevant in this aspect as it allows controlled experimental conditions and postmortem tissue for biochemical and morphological examinations. We here describe results from a pilot study in an experimental rat model suitable for introducing iron deficiency in the developing brain.

This model was utilized for examination of the potential to reverse eventual changes in fetal brain iron by means of maternal parenteral (i.e. subcutaneous) iron administration.

\section{Methods}

Eight female rats aged postnatal day 42 (P42) were fed a normal diet with an iron content of $158 \mathrm{mg} / \mathrm{kg}$ (Altromin, Germany) (control rats (group N)) for six + six weeks, equal to 12 weeks. In parallel, 56 female rats were also initially fed the normal diet for six weeks until they reached P42. Then they were given an iron deficient diet for another six weeks with an iron content of $5.2 \mathrm{mg} / \mathrm{kg}$ (Altromin, Germany). The rats were fertilized by male rats fed the normal diet and maintained on the two different diets. For iron supplementation, the maternal rats fed the diet with a low iron content were injected subcutaneously with iron isomaltoside (Monofer ${ }^{\circ}$, Pharmacosmos A/S, Holbaek, Denmark) at a dose of $80 \mathrm{mg} / \mathrm{kg}$ on day E0 (the day of conception, group A), E14 (14 days after conception, group B), or the day of birth, day P0 (group C). Twelve pups aged P0 (date of birth) were obtained from the pregnant rats of groups A, B, C, and N (controls), euthanized and examined for brain iron levels. The Danish Experimental Animal Inspectorate under the Ministry of Food and Agriculture (permission no. 2013-15-293400776) approved the handling of the animals in this study.

The brain stem of the pups were dissected and used for detection of the concentration of iron by Inductively Coupled Argon Plasma with Optical Emission Spectrometry detection (ICP-OES) (ICAP 6300 Duo View, Thermo Scientific). In brief, the tissue samples were freeze dried, homogenized, and transferred to Teflon vessels. The samples were then digested using microwave assisted acid digestion with $8 \mathrm{~mL}$ concentrated nitric acid for $10 \mathrm{~min}$ at $1200 \mathrm{~W}$. Four cooled digestates were diluted to volume with ultrapure water and transferred to plastic flasks, and allowed to settle before being analyzed for iron. Iron concentration was determined by ICP-OES. All were measured axially at two to three wavelengths. All data are shown as mean \pm standard error of the mean (SEM). Oneway Analysis of Variance (ANOVA) analysis with Tukey's multiple comparison post-hoc tests was performed using the GraphPad Prism version 6.01 software in order to compare data from all groups to controls or to the respective dietary group (e.g. A vs B). Values of $p<0.05$ were considered statistically significant.

\section{Results}

The pups of iron deficient mothers that did not receive parenteral iron during pregnancy $(C)$ had a significant, $40 \%$ reduction $(6.2 \pm 0.3 \mu \mathrm{g} / \mathrm{g})$ of the iron level in the brain compared to pups of the control mothers $(\mathrm{N}, 10.5$ $\pm 0.3 \mu \mathrm{g} / \mathrm{g}$ ) (Fig. 1). In contrast, pups of iron deficient mothers that received parenteral iron two thirds into the pregnancy (E14, B group) had amounts of brain iron levels that did not differ from the control group at birth (Fig. 1). Pups of mothers treated with iron at the day of conception (E0, A) had raised concentrations of iron compared to the group that did not receive iron (Fig. 1).

\section{Discussion}

We have in this brief communication described a rat model of iron deficiency in which maternal iron restriction during pregnancy led to significantly lower levels of iron in the brains of newborn rats compared to levels in 


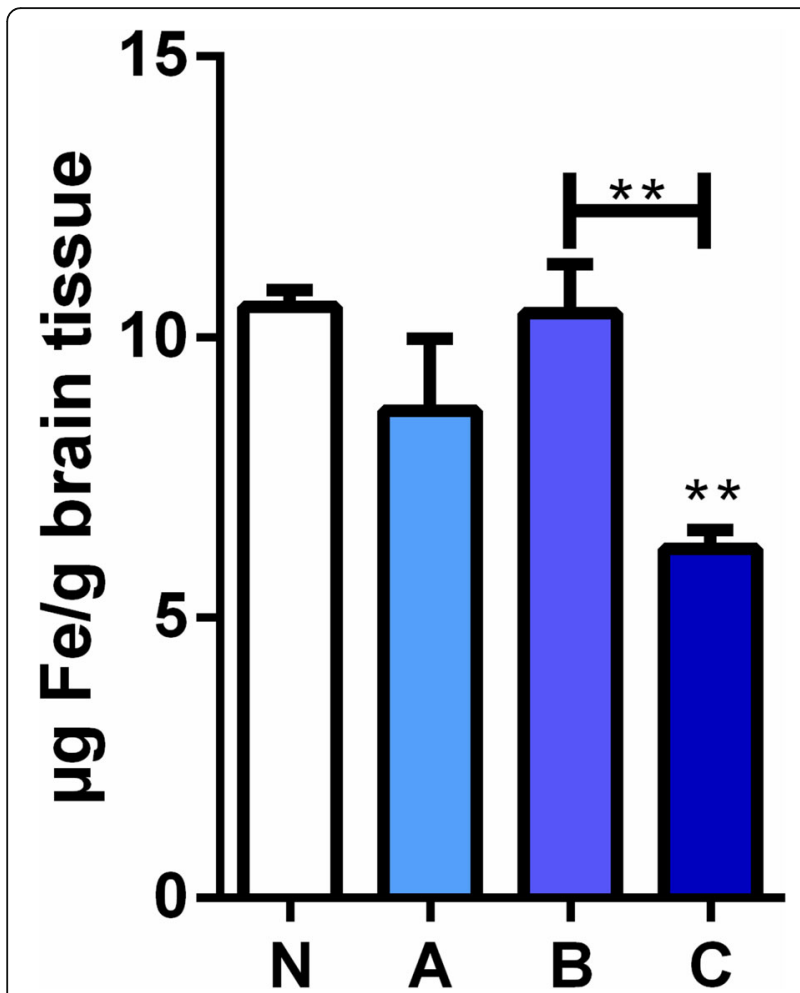

Fig. 1 The levels of iron in brains of newborn rat pups of mothers fed with iron deficient diet with or without supplementation. In the brain iron (Fe) is significantly lower in the pups from mothers on the iron deficient diet (C group) compared to the pups from mothers on the iron deficient diet treated with parental iron isomaltoside at E 14 (B group) and pups from normal fed mothers equal to an iron sufficient diet ( $\mathrm{N}$ group). The A group which represents pups from mothers on the iron deficient diet treated with parental iron isomaltoside at EO did not differ from either of the B or N groups, but it was still higher than in C. Data are presented as mean \pm SEM $(n=4-5)$. ${ }^{*} p<0.01$ pups of iron sufficient fed mothers. Parenteral administration with iron isomaltoside to the pregnant female rats with iron deficiency restored normal levels of iron in the brain of the newborn pups. Hence, the administered iron passed the placenta and fetal blood brain barrier. The parental supply with iron isomaltoside also restored hemoglobin level in the developing rat, as at the day of birth the newborn rats of ID mothers (group C) had a significantly lower hemoglobin level $(3.6 \pm 0.18 \mathrm{mmol} / \mathrm{L})$ than the newborn rats of mothers fed a normal diet (6.02 \pm $0.09 \mathrm{mmol} / \mathrm{L}$ ) (Moos et al., in preparation).

In future studies, the translational model of the present brief study may be applied to examine morphological and biochemical consequences of iron deficiency and iron deficiency treatment in the developing fetal human brain if confirmed in extended and repeat studies. Although this will be difficult to perform in humans and thereby a limitation in the translation of the present study, it should nonetheless be conceivable for clinical research by administering iron to human mothers early and later in pregnancy. Thereby, it should be possible to measure serum concentrations of iron in neonates to follow the cognitive and behavioral outcome of children over years.

\section{Conclusions}

This translational study may provide useful data allowing for optimal planning and transition into clinical trials as the translational model may be extended to also include assessment of associated behavioral consequences and potential correlations to morphological and biochemical consequences of iron deficiency and iron deficiency treatment in the developing fetal brain. The model also represents a unique model making it possible to examine details regarding regulation of maternally administered iron across the placenta as well as the fetal blood-brain barrier. Further, it allows future studies of optimal timing and dose levels of iron treatment in the pregnant mother to optimize fetal brain development in iron deficient mothers.

\section{Acknowledgments}

The authors would like to thank Merete Fredsgaard and Luise Bolther for technical assistance in the metal analyses, and the medical writing assistance of Eva-Maria Damsgaard Nielsen in editing the manuscript. Eva-Maria Damsgaard Nielsen is employed at Pharmacosmos A/S.

\section{Funding}

The work was supported by grants from the Danish Innovation Fund (Grant no: 014-2011-5). Publication charges for this article have been funded by Pharmacosmos A/S.

\section{Availability of data and materials}

The authors declare that all material and data achieved from analyses are available.

\section{About this supplement \\ This article has been published as part of Reproductive Health Volume 15 Supplement 1, 2018: Improving pregnancy outcomes - Proceedings of the 2nd International Conference on Maternal and Newborn Health: Translating Research Evidence to Practice. The full contents of the supplement will be available online at https://reproductive-health-journal.biomedcentral.com/ articles/supplements/volume-15-supplement-1.}

\section{Authors' contributions}

All authors contributed to conception and design and data acquisition or analysis and interpretation of data, and all authors reviewed the manuscript, contributed each with important intellectual content during the manuscript writing, and approved the final version. The authors agree to be accountable for all aspects of the work in ensuring that questions related to the accuracy or integrity of any part of the work are appropriately investigated and resolved.

\section{Ethics approval and consent to participate}

The authors declare all ethics approved for the study. The study is purely derived from experiments in small rodents, and permit obtained from The Danish Experimental Animal Inspectorate under the Ministry of Food and Agriculture (permission no. 2013-15-2934-00776). 


\section{Publisher's Note}

Springer Nature remains neutral with regard to jurisdictional claims in published maps and institutional affiliations.

Published: 22 June 2018

\section{References}

1. Zimmermann MB, Hurrell RF. Nutritional iron deficiency. Lancet. 2007; 370:511-20.

2. Scholl TO. Iron status during pregnancy: setting the stage for mother and infant. Am J Clin Nutr. 2005;81:1218S-22S.

3. Markova V, Norgaard A, Jørgensen KJ, Langhoff-Roos J. Treatment for women with postpartum iron deficiency anaemia. Cochrane Database Syst Rev. 2015;8:CD010861. https://doi.org/10.1002/14651858.CD010861.pub2.

4. Peña-Rosas JP, De-Regil LM, Garcia-Casal MN, Dowswell T. Daily oral iron supplementation during pregnancy. Cochrane database Syst Rev. 2015;7: CD004736. Available from: doi: https://doi.org/10.1002/14651858.CD004736.pub5.

5. Haider BA, Olofin I, Wang M, Spiegelman D, Ezzati M, Fawzi WW. Anaemia, prenatal iron use, and risk of adverse pregnancy outcomes: systematic review and meta-analysis. BMJ. 2013;346:f3443.

6. Alwan NA, Cade JE, McArdle HJ, Greenwood DC, Hayes HE, Simpson NA. Maternal iron status in early pregnancy and birth outcomes: insights from the baby's vascular health and iron in pregnancy study. Br J Nutr. 2015;113:1985-92.

7. Lozoff B. Iron deficiency and child development. Food Nutr Bull. 2007; 28:S560-71

8. Laskey J, Webb I, Schulman HM, Ponka P. Evidence that transferrin supports cell proliferation by supplying iron for DNA synthesis. Exp Cell Res. 1988;176:87-95.

9. Siddappa AM, Rao R, Long JD, Widness JA, Georgieff MK. The assessment of newborn iron stores at birth: a review of the literature and standards for ferritin concentrations. Neonatology. 2007;92:73-82.

10. Greminger $A R$, Lee $D L$, Shrager $P$, Mayer-Pröschel M. Gestational iron deficiency differentially alters the structure and function of white and gray matter brain regions of developing rats. J Nutr. 2014;144:1058-66.

11. Heath AL, Fairweather-Tait SJ. Clinical implications of changes in the modern diet: iron intake, absorption and status. Best Pract Res Clin Haematol. 2002;15:225-41.

12. Skjørringe T, Burkhart A, Johnsen KB, Moos T. Divalent metal transporter (DMT1) in the brain: implications for a role in iron transport at the blood-brain barrier, and neuronal and glial pathology. Front Mol Neurosci. 2015;8:19.

13. Lozoff B, Jimenez E, Hagen J, Mollen E, Wolf AW. Poorer behavioral and developmental outcome more than 10 years after treatment for iron deficiency in infancy. Pediatrics. 2000;105:E51.

14. Chen M-H, Su T-P, Chen Y-S, Hsu J-W, Huang K-L, Chang W-H, et al. Association between psychiatric disorders and iron deficiency anemia among children and adolescents: a nationwide population-based study. BMC Psychiatry. 2013;13:161.

15. Eseh R, Zimmerberg B. Age-dependent effects of gestational and lactational iron deficiency on anxiety behavior in rats. Behav Brain Res. 2005;164:214-21.

16. Lozoff B, Clark KM, Jing Y, Armony-Sivan R, Angelilli ML, Jacobson SW. Dose-response relationships between iron deficiency with or without anemia and infant social-emotional behavior. J Pediatr. 2008;152:696-702.

17. Sawada T, Konomi A, Yokoi K. Iron deficiency without anemia is associated with anger and fatigue in young Japanese women. Biol Trace Elem Res. 2014;159:22-31.

18. Radlowski EC, Johnson RW. Perinatal iron deficiency and neurocognitive development. Front Hum Neurosci. 2013;7:585

19. Grantham-McGregor S, Ani C. A review of studies on the effect of iron deficiency on cognitive development in children. J Nutr. 2001;131:649S-68S

20. Beard JL. Why iron deficiency is important in infant development. J Nutr. 2008;138:2534-6.

21. Tamura T, Goldenberg RL, Hou J, Johnston KE, Cliver SP, Ramey SL, et al. Cord serum ferritin concentrations and mental and psychomotor development of children at five years of age. J Pediatr. 2002;140:165-70.

22. Parsons AG, Zhou SJ, Spurrier NJ, Makrides M. Effect of iron supplementation during pregnancy on the behaviour of children at early school age: long-term follow-up of a randomised controlled trial. $\mathrm{Br} J$ Nutr. 2008;99:1133-9.

23. Lewis SJ, Bonilla C, Brion MJ, Lawlor DA, Gunnell D, Ben-Shlomo Y, et al. Maternal iron levels early in pregnancy are not associated with offspring IQ score at age 8 , findings from a Mendelian randomization study. Eur J Clin Nutr. 2014;68:496-502.

\section{Ready to submit your research? Choose BMC and benefit from:}

- fast, convenient online submission

- thorough peer review by experienced researchers in your field

- rapid publication on acceptance

- support for research data, including large and complex data types

- gold Open Access which fosters wider collaboration and increased citations

- maximum visibility for your research: over $100 \mathrm{M}$ website views per year

At BMC, research is always in progress.

Learn more biomedcentral.com/submissions 